\title{
Positive sampling artifact of carbonaceous aerosols and its influence on the thermal-optical split of OC/EC
}

\author{
Y. Cheng ${ }^{1}$, K. B. He ${ }^{1}$, F. K. Duan ${ }^{1}$, M. Zheng ${ }^{2}$, Y. L. Ma ${ }^{1}$, and J. H. Tan ${ }^{1}$ \\ ${ }^{1}$ Department of Environmental Science and Engineering, Tsinghua University, Beijing, China \\ ${ }^{2}$ School of Earth and Atmospheric Sciences, Georgia Institute of Technology, Atlanta, Georgia, USA
}

Received: 7 June 2009 - Published in Atmos. Chem. Phys. Discuss.: 22 June 2009

Revised: 28 August 2009 - Accepted: 1 September 2009 - Published: 29 September 2009

\begin{abstract}
Accurate measurement of carbonaceous aerosols is challenging, due to the sampling artifact and the problems of the split of OC/EC. Two approaches have been used to account for the positive artifact: backup quartz approach in which a backup quartz filter is placed either behind a front quartz filter (QBQ) or in a parallel port behind a Teflon filter (QBT), and organic denuder approach in which an organic denuder is placed upstream of the quartz filter. Both approaches were evaluated in Beijing, China, from January to February 2009 . $10 \%$ of the OC captured by the bare quartz filter was from the positive artifact. The origin of backup OC was quantitatively evaluated by the denuder-based method. All of the QBQ OC was from gaseous organics passing through the front filter, but the QBQ had not reached equilibrium with gas phase due to the relative small sampling volume resulting in an undercorrection of the positive artifact by $3.7 \%$. QBT OC was from both gaseous organics passing through the front filter (82\%) and the evaporated organic carbon (18\%), thus overcorrecting the positive artifact by $6.3 \%$. Even the positive artifact-contributed QBT OC was found to overestimate the positive artifact, perhaps due to the difference in the adsorption properties of the loaded filter and the filter without particle loading. Re-partitioning of PC and EC was performed by the multiple linear regression approach. The attenuation coefficient of $\mathrm{PC}$ was twofold higher than that of EC, indicating PC was darker than EC, resulting in the underestimation of native EC by TOT-split-EC. It was also found that PC formed on the bare quartz filter $\left(45.56 \mathrm{~m}^{2} / \mathrm{g}\right)$ was darker than that formed on the denuded filter $\left(38.64 \mathrm{~m}^{2} / \mathrm{g}\right)$, indicating that the underestimation for the bare quartz filter was more significant.
\end{abstract}

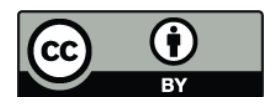

Correspondence to: K. B. He (hekb@tsinghua.edu.cn)

\section{Introduction}

In recent years, advances have occurred in the measurement of ambient fine particulate matter $\left(\mathrm{PM}_{2.5}\right)$. Two trends are especially noticeable. The first trend is the development of the monitoring network on a regional scale. For example, the US Environment Protection Agency (EPA) has established three interlaced networks (Solomon et al., 2003): (1) the first network includes about $1100 \mathrm{PM}_{2.5}$ Federal Reference Method (FRM) monitors, which provide 24-h integrated $\mathrm{PM}_{2.5}$ mass data to estimate population exposure; (2) the second network consists of the US EPA National $\mathrm{PM}_{2.5}$ chemical Speciation Trends Network (STN) and the Interagency Monitoring of Protected Visual Environments network (IMPROVE), which provide 24-h integrated chemical composition data that support the US air quality program objectives (US EPA, 2004); (3) the third network, the US EPA's PM Supersites Program, includes eight Supersite projects which are designed to evaluate advanced monitoring methods for their potential transition to routine monitoring networks, together with the evaluation of models.

The second trend is the development of continuous monitoring (Chow et al., 2008), such as the TEOM for the realtime measurement of the $\mathrm{PM}_{2.5}$ mass, the Sunset Laboratory Carbon Aerosol Monitor for the semi-continuous measurement of the OC and EC, and the continuous ion chromatography of water-soluble ions (Sciare et al., 2007). Continuous monitoring could provide an additional dimension in source apportionment, where source variations and meteorological variables could be included in the analysis, since highly timeresolution sampling enables measurement of short term duration variations in pollutant concentration due to emissions and meteorological variations (Wexler and Johnston, 2008).

Despite the progress mentioned above, the speciation measurement of $\mathrm{PM}_{2.5}$, especially the measurement of the carbonaceous components (both integrated and semi-continuous) still has challenges. Among the factors

Published by Copernicus Publications on behalf of the European Geosciences Union. 
that complicate the measurement of carbonaceous aerosols are the sampling artifact, the split of OC (organic carbon) and EC (elemental carbon), and the ratio of converting carbon mass to organic matter mass (Huebert and Charlson, 2000; Jacobson et al., 2000; Turpin et al., 2000; Turpin and Lim, 2001).

The sampling artifact includes both the positive artifact caused by the adsorption of gaseous organics and the negative artifact caused by the evaporation of collected particulate organic carbon. One way to account for the positive artifact (backup quartz approach) is to place a backup quartz filter, either behind a front quartz filter (QBQ) or in a parallel port behind a Teflon filter (QBT). The OC measured by QBQ or QBT provides an estimation of the gaseous organics adsorbed by the front quartz filter, or the positive artifact. Another approach to eliminate the positive artifact (organic denuder approach) is to place an organic denuder upstream of quartz filter, in which the gaseous organics are removed by diffusion to an adsorbent surface such as activated carbon (Eatough et al., 1993, 1999, 2003a; Mikuška et al., 2003) and polystyrene-divinylbenzene resin (XAD, Fan et al., 2003, 2004a, b). But the use of an organic denuder may induce a larger negative artifact, since the removal of gaseous organics enhances evaporation of particulate OC collected on the quartz filter. As a result, a backup quartz filter should be included (Viana et al., 2006a, b, 2007). In some studies, a highly adsorbent backup filter, such as an activated carbon impregnated filter (CIF or CIG, Eatough et al., 2001), or XAD impregnated quartz filter (XAD-Q, Fan et al., 2003; Swartz et al., 2003), was used to get a higher collection efficiency of evaporated organic carbon. OC determined by the denuded quartz filter and the backup filter is usually defined as NVOC (nonvolatile organic carbon) and SVOC (semivolatile organic carbon), respectively. As shown in Fig. 1, SVOC could account for a substantial fraction (10 70\%) of the organic particulate matter. For the determination of gas-particle partitioning of individual organics (such as PAHs), PUF (Lane et al., 2000; Peters et al., 2000; Eiguren-Fernandez et al., 2004) and XAD resin (Gundel et al., 1995a, b; Temime-Roussel et al., 2004a, b; Goriaux et al., 2006) could also be used as backup adsorbent. A critical review of the organic denuder approach has been performed by Cheng et al. (2009). More recently, Ortiz et al. (2006, 2009) used an O-(2,3,4,5,6-pentafluorobenzyl) hydroxylamine (PFBHA) coated denuder and PFBHA impregnated quartz filter to determine the phase distribution of bi-functional carbonyls.

Special attention should be paid to denuder breakthrough when referring to the results from denuder-based method. Breakthrough is the amount of gaseous organics that are not removed by the denuder and subsequently adsorbed by the filter. The influence of breakthrough would be more significant when the adsorbent backup filter is included. For example, though the activated carbon denuder removed all the gaseous organics that could be adsorbed by quartz filter,

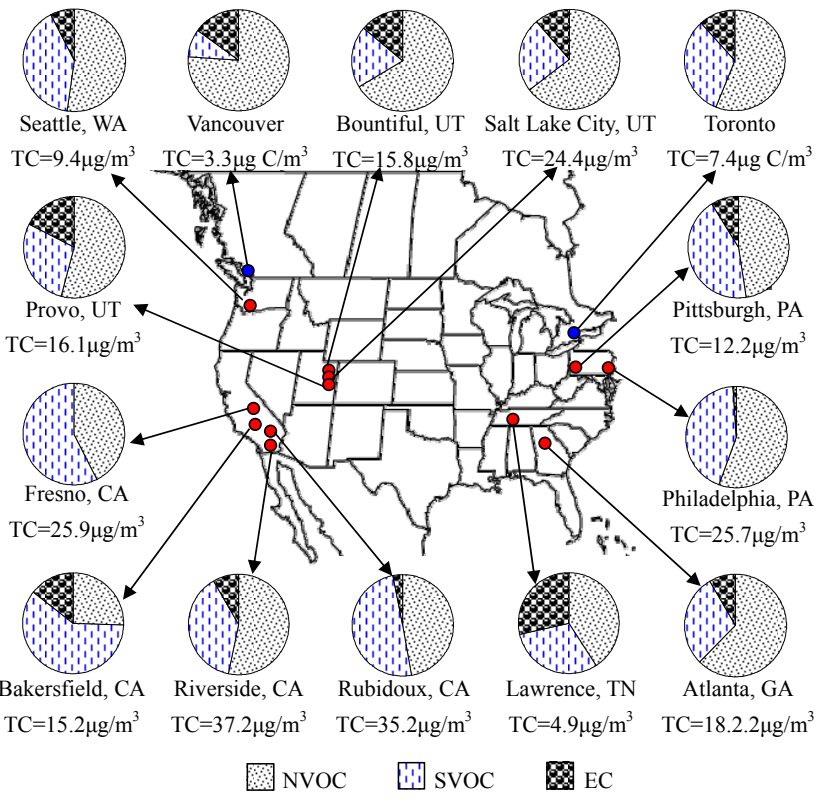

Fig. 1. NVOC, SVOC and EC concentrations determined in 14 North American cities. TC is the concentration of total carbonaceous components. Results from PC-BOSS sampler (CIF denuder in combination with backup CIF or CIG filter), which is developed by D. J. Eatough and co-workers, are shown by red dots; results from IOGAPS sampler (XAD denuder in combination with backup XAD-Q filter), which is evaluated by J. R. Brook and co-workers, are shown by blue dots. Data from Cheng et al. (2009).

breakthrough constituted $17 \%, 22 \%$ and $80 \%$ of the SVOC concentration (measured by the backup CIF filter), for concentrations of SVOC above 2, between 1 and 2, and below $1 \mu \mathrm{g} / \mathrm{m}^{3}$ (Modey et al., 2001). As a result, breakthrough should be measured and considered in correction when using the denuder-based method.

Though may be complicated by breakthrough, an organic denuder in combination with a backup filter is an effective approach to eliminate the positive and negative artifacts encountered by the measurement of carbonaceous aerosols. Comparison between the backup quartz and the organic denuder approach could provide important insights into the sampling artifact problem (Cheng et al., 2009), but few studies have been published.

Another concern regarding the measurement of carbonaceous aerosols is the split of OC/EC. A variety of analytical methods have been developed to separate $\mathrm{OC}$ and EC, such as the thermal method developed by Novakov (1982), the thermal manganese oxidation method developed by Fung (1990), and the thermal-optical method developed by Huntzicker et al. (1982). Ideally, a loaded filter is exposed to a prescribed temperature protocol first in an inert atmosphere (He) to determine $\mathrm{OC}$ and then in an oxidizing atmosphere $\left(\mathrm{He} / \mathrm{O}_{2}\right)$ to determine EC. But a fraction of OC chars or pyrolyzes in the inert mode of the analysis, which can absorb light and requires an oxidizing atmosphere to evolve off the filter. This 
fraction of OC is called pyrolyzed organic carbon, or PC. Thermal-optical method has been developed to account for the PC formation (Huntzicker et al., 1982), in which the carbon evolved in the oxidizing atmosphere that is necessary to return the filter reflectance or transmittance to its initial value is considered as PC. As pointed out by Yang and Yu (2002), the PC correction in the thermal-optical methods depends on one of the following two assumptions: (1) PC evolves before the native EC in the oxidizing atmosphere, or (2) PC and native EC have the same light attenuation coefficient. But both of these assumptions are invalid. The co-evolution of PC and EC has been demonstrated by Yu et al. (2002), Yang and $\mathrm{Yu}$ (2002), and Subramanian et al. (2006); the difference in the light attenuation coefficient has been demonstrated by Chow et al. (2004) and Subramanian et al. (2006). Moreover, the peak inert mode temperature (the temperature of the last step in the He mode) has a substantial influence on the EC measured, which also adds to the challenge in the thermal-optical split of OC/EC (Conny et al., 2003; Sciare et al., 2003; Chow et al., 2005a). Too high of a peak inert mode temperature (such as $870^{\circ} \mathrm{C}$ used in the NIOSH protocol) may underestimate the $\mathrm{EC}$ concentration due to the premature EC evolution (Chow et al., 2001), while too low of a peak inert mode temperature (such as $550^{\circ} \mathrm{C}$ used in the IMPROVE protocol) may overestimate the EC concentration due to OC not completely evolving or pyrolyzing into non-light-absorbing carbon (Schauer et al., 2003; Subramanian et al., 2006). More recently, the influence of brown carbon (Andreae and Gelencsér, 2006), or humic like substances (HULIS), on the split of OC and EC has been found to be a concern (Reisinger et al., 2008; Wonaschütz et al., 2009).

According to the results from Subramanian et al. (2006) and Schauer et al. (2003), it is suggested using the following criterion to choose the peak inert mode temperature: (1) the laser signal should reach its minimum value in the last step of the He mode, and (2) should not increase until the $\mathrm{He} / \mathrm{O}_{2}$ mode. It should be pointed out that the choice of temperature protocol is still a matter of debate and more researches are essential. The criterion above was drawn from the few studies available, and as a result was still limited. There are other factors that should be considered. For example, the last OC peak in the He mode should be well-separated with the first EC peak in the $\mathrm{He} / \mathrm{O}_{2}$ mode, which means the carbon signal should return to its baseline at the end of the $\mathrm{He}$ mode (ideally), rather than significantly above the baseline and with a long tail. Increasing the peak inert mode temperature would make the last OC peak better separated with the first EC peak, but it may also induce the premature EC evolution. As a result, these additional factors should be considered carefully and should be balanced with the current criterion.

As mentioned above, the partitioning of $\mathrm{PC}$ and $\mathrm{EC}$ automatically done by the analyzer is complicated by the coevolution of PC and EC, and the difference in their light attenuation coefficient. As a result, re-partitioning of PC and
EC based on the calculation of their light attenuation coefficients could provide important insights into the problem of split of OC/EC (Chow et al., 2004; Subramanian et al., 2006).

In this article, we used a five channel $\mathrm{PM}_{2.5}$ sampler, including both the backup quartz approach channel and the organic denuder approach channel, to investigate the effect of the sampling artifact on OC measurements in Beijing, China. In addition, as pointed out by Chow et al. (2004), charring of the adsorbed gaseous organics may account for a substantial fraction of PC formation. As a result, influence of the sampling artifact on the split of OC/EC was also estimated.

\section{Methods}

\subsection{Overview of the campaign}

The sampling campaign reported here is the first stage of the "Improved Measurement of Carbonaceous Aerosols in Beijing" (IMCA) project, which is a major part of the "Carbonaceous Species and Complex Mechanism of Particulate Air Pollution" program. The primary aims of the campaign include: (1) evaluation of the capacity of the activated carbon denuder to eliminate the positive artifact; (2) evaluation of the origin of OC collected by the backup quartz filter behind a front quartz filter and in a parallel port behind a Teflon filter; (3) evaluation of the thermal-optical split of OC/EC and the influence of positive artifact on PC formation.

\subsection{Sample collection}

Ambient $\mathrm{PM}_{2.5}$ samples were collected at the Tsinghua University campus in Beijing, China. Details of the site were provided by $\mathrm{He}$ et al. (2001). Topography, meteorology, and the status of atmospheric particulate pollution of Beijing were summarized by Chan and Yao (2009), and the economic and energy consumption characteristics were described by Guinot et al. (2007).

29 sets of daily $\mathrm{PM}_{2.5}$ samples were collected from 9 January to 12 February 2009 by a Spiral Ambient Speciation Sampler (SASS) developed by MetOne. The SASS has five separate channels, operated through a common controller and pump. Each channel contains a sharp cut cyclone which is designed to give a $2.5 \mu \mathrm{m}$ cutpoint with a slope and cutpoint similar to the FRM when operated at $6.7 \mathrm{Lpm}$ (Peters et al., 2001; Solomon et al., 2003). Configurations of the five channels are shown in Table 1. Channel 1 and 2 were organic denuder approach channels, to determine nonvolatile organic carbon (NVOC) and OC evaporated from the front quartz filter and the front Teflon filter. Channels 3 and 4 were backup quartz approach channels. Channel 5 was the breakthrough channel, in which a quartz filter (TSP filter) was placed upstream of the denuder. As a result, OC collected by the sequential quartz filters in channel 5 was from the adsorption of gaseous organics that were not removed by the denuder, which was defined as breakthrough OC. 
Table 1. Configurations of the five channel SASS sampler.

\begin{tabular}{llllll}
\hline Channel & 1 & 2 & 3 & 4 & 5 \\
\hline TSP Filter $^{\mathrm{a}}$ & NA & NA & NA & NA & Quartz (TSP) \\
Organic Denuder & Activated Carbon & Activated Carbon & NA & NA & Activated Carbon \\
Front Filter & Quartz (DQ) & Teflon & Quartz (BQ) & Teflon & Quartz (BT-Q) \\
Backup Filter & Quartz (D-QBQ) & Quartz (D-QBT) & Quartz (QBQ) & Quartz (QBT) & Quartz (BT-QBQ) \\
\hline
\end{tabular}

${ }^{\mathrm{a}}$ TSP filter was placed upstream of the cyclone for the determination of breakthrough. ${ }^{\mathrm{b}}$ Abbreviation in parentheses.

The activated carbon denuder (provided by MetOne) is $20 \mathrm{~mm}$ long and $38 \mathrm{~mm}$ in diameter with about $1000,1 \mathrm{~mm}^{2}$ channels, for a typical residence time of $0.18 \mathrm{~s}$ at $6.7 \mathrm{Lpm}$. All filters used were $47 \mathrm{~mm}$ in diameter. The diameter of the area with particle loading is $38 \mathrm{~mm}$, inducing a face velocity of $9.8 \mathrm{~cm} / \mathrm{s}$. The Teflon (R2PJ047) and quartz filters (2500 QAT-UP) were both from Pall Corp. (Ann Arbor, MI). All of the quartz filters used throughout the campaign were taken from the same lot, to avoid the interlot variability in adsorption capacity (Kirchstetter et al., 2001). The quartz filters were pre-baked at $550^{\circ} \mathrm{C}$ in air for $24 \mathrm{~h}$. 14 quartz filters were kept as blank. The average OC concentration of the blank filters was $0.45 \mu \mathrm{gC} / \mathrm{cm}^{2}$, and no EC was detected. All the data reported in this article were corrected by the filter blank concentration without special statement.

\subsection{Sample analysis}

All the quartz filters were analyzed using a DRI Model 2001 thermal/optical carbon analyzer (Atmoslytic Inc., Calabasas, CA) (Chow et al., 2005b). The IMPROVE-A temperature protocol was used (Chow et al., 2007), which heated the sample to $140,280,480,580^{\circ} \mathrm{C}$ in pure $\mathrm{He}$ atmosphere to determine $\mathrm{OC} 1 \sim \mathrm{OC} 4$ and subsequentially to $580,740,840^{\circ} \mathrm{C}$ in $2 \% \mathrm{O}_{2} / 98 \% \mathrm{He}$ atmosphere to determine $\mathrm{EC} 1 \sim \mathrm{EC} 3$, with the residence time defined by the flattening of carbon signals. $\mathrm{PC}$ is defined as the carbon that is measured after the introduction of $\mathrm{He} / \mathrm{O}_{2}$ atmosphere at $580^{\circ} \mathrm{C}$ but before transmittance returns to its initial value. $\mathrm{OC}$ is defined as $\mathrm{OC} 1+\mathrm{OC} 2+\mathrm{OC} 3+\mathrm{OC} 4+\mathrm{PC}$, and $\mathrm{EC}$ is defined as EC1+EC2+EC3-PC. The thermal-optical transmittance (TOT) charring correction is implemented here, since the re-partitioning of PC and EC is based on the attenuation coefficient which is calculated from transmittance values (See Sect. 3.3). An example thermogram is shown in Fig. 2. In Fig. 2, the transmittance signal reaches its minimum value in OC-4 step, and does not increase until the introduction of $\mathrm{O}_{2}$ in EC-1 step, according with the criterion in Sect. 1.

It was noticed that the reflectance signal began to increase in the OC-4 step, while the transmittance signal remained flat (Fig. 2). This was the case for all the 10 sets of filters (DQ and $\mathrm{BQ}$ ), in which the minimum of transmittance signal were detectable. The increase of the reflectance signal was

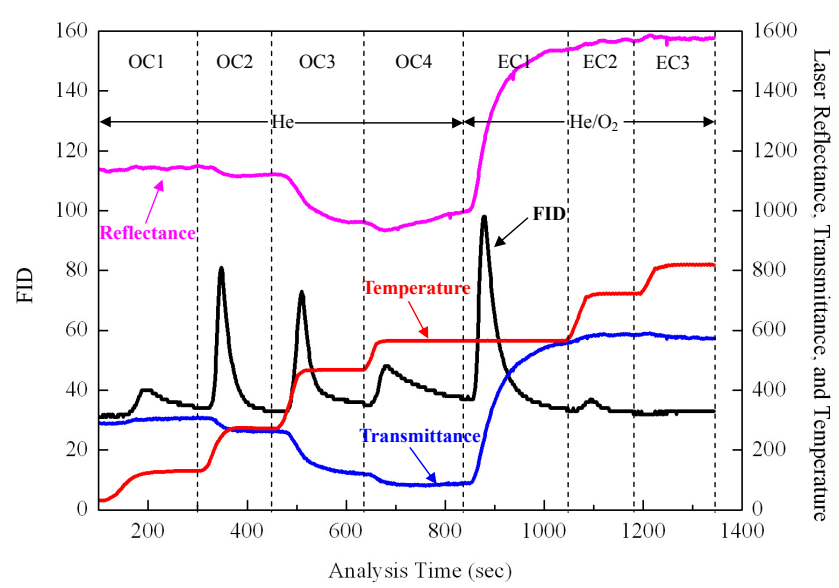

Fig. 2. Example thermogram $\left(\mathrm{TC}=16.27 \mu \mathrm{gC} / \mathrm{cm}^{2}\right.$ ) for IMPROVE-A temperature protocol.

also found in the other 19 sets of filters (DQ and BQ). The increase was caused by the loss of light-absorbing carbon (PC or EC or both). It seemed that the temperature of the OC-4 step should be reduced to avoid the loss of light-absorbing carbon, but due to the following three factors, the OC-4 step temperature was not reduced. (1) The transmittance signal was flat, indicating the loss of light-absorbing carbon should not be significant. (2) Even at the current temperature, the split of OC/EC maybe affected by the artifact that OC not completely evolving or pyrolyzing into non-light-absorbing carbon. (3) The current temperature was close to the lower limit of the peak inert mode temperature $\left(550^{\circ} \mathrm{C}\right)$ of different thermal-optical protocols. It should be pointed out that Schauer et al. (2003) draw the conclusion that IMPROVE temperature protocol may result in OC not completely evolving according to the evidence that the transmittance signal continued to drop at the start of the $\mathrm{He} / \mathrm{O}_{2}$ mode. As shown in Fig. 2, no drop of transmittance signal was seen after the introduction of $\mathrm{O}_{2}$. As a result, though could not be excluded, the artifact that $\mathrm{OC}$ not completely evolving should not be significant.

It was also noticed that the carbon signal (FID) did not return to its baseline at the end of the OC-4 step. It seemed that temperature of the OC-4 step should be increased to make a 
better separation between OC-4 and EC-1. But the increase would enhance the loss of light-absorbing carbon, and as a result, the OC-4 step temperature was not increased either.

After considering and balancing all the factors above, the IMPROVE-A temperature protocol was acceptable for these sets of Beijing aerosol.

\section{Result}

\subsection{Evaluation of the activated carbon denuder}

The use of an organic denuder may cause additional artifacts that complicate the measurement of carbonaceous aerosols, such as: (1) particle loss due to the diffusion to the walls of the denuder, (2) contamination problems of EC from the denuder charcoal particles, (3) evaporation of particulate organic carbon during transportation through the denuder, due to depletion of gaseous organics, and (4) denuder breakthrough. As a result, an evaluation of the denuder is essential.

\subsubsection{Particle loss}

Particle loss could be evaluated by comparing concentrations of EC, which is nonvolatile and the size distribution of which peaks at aerodynamic diameters below $1.0 \mu \mathrm{m}$ (Venkataraman and Friedlander, 1994; Huang and Yu, 2008), measured by the denuded quartz filter (DQ) and the bare quartz filter (BQ). DQ EC and BQ EC were compared in Fig. 3. As shown in Fig. 3, the particle loss in the denuder was negligible. Paired t-test also showed that EC values determined by DQ and BQ were not significantly different at a $95 \%$ level of confidence $(p=0.581)$.

\subsubsection{Contamination problems of EC}

Shedding of the denuder material (activated carbon) has been observed by Subramanian et al. (2004) and Viana et al. (2006). The denuder used in this study did not exhibit any shedding, since no tiny charcoal particles were observed on the denuded quartz filter (DQ), Teflon filter (in channel 2), and the front quartz filter in the breakthrough channel (BT-Q) throughout the whole sampling period. Moreover, the result of OC/EC analysis showed that no EC was detected on the BT-Q. As a result, the contamination problems of EC were minimal.

\subsubsection{Residence time in denuder}

The denuder used in this study was designed such that the residence time of particles in the denuder was $0.18 \mathrm{~s}$, less than $0.2 \mathrm{~s}$, a critical value suggested by Kamens and Coe (1997) and Strommen and Kamens (1999) to avoid offgassing of particulate organic carbon. It should be pointed out that though in some studies a residence time of more than

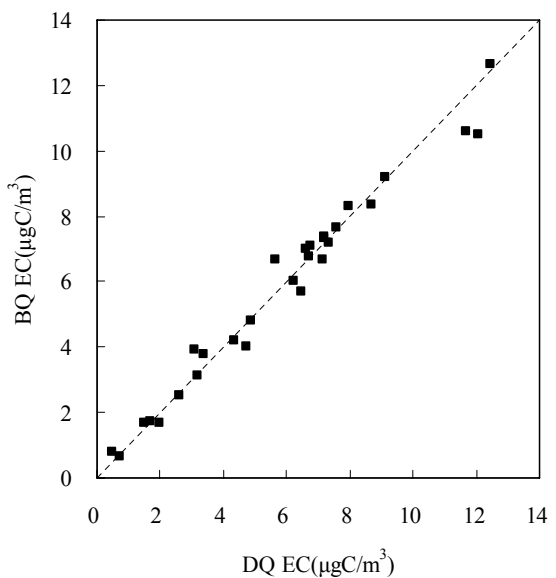

Fig. 3. Comparison of DQ EC and BQ EC.

$1 \mathrm{~s}$ was adopted, no evidence of the loss of organics from particles was seen (Eatough et al., 1993).

\subsubsection{Denuder breakthrough and efficiency}

In the breakthrough channel, particles were collected by the TSP filter in front of the $\mathrm{PM}_{2.5}$ cyclone (Table 1), and gaseous organics were captured by the organic denuder. As a result, OC collected by the front (BT-Q) and backup (BTQBQ) quartz filter was from breakthrough. Comparable OC loadings were determined by the front and backup filters, averaging at 0.42 and $0.46 \mu \mathrm{gC} / \mathrm{cm}^{2}$ respectively, which were also comparable with the filter blank values (averaging at $0.45 \mu \mathrm{gC} / \mathrm{cm}^{2}$ ), as shown in Fig. 4. As a result, there was no breakthrough (that could be adsorbed by the quartz filter), and the efficiency of the activated carbon denuder to eliminate the positive artifact was $100 \%$ during the sampling period. Negligible amounts of breakthrough $\mathrm{OC}$ on the front quartz filter was also reported by Modey et al. (2001), Pang et al. (2002a, b), and Mader et al. (2001).

The field blank filter (or handling blank filter) was usually loaded onto the sampler and removed after one minute (without any air flow), as a result, OC determined by BT-Q and BT-QBQ could provide an upper limit for the field blank. Since both the BT-Q OC and BT-QBQ OC were comparable with the filter blank concentration, it could be concluded that the field blank concentration should also be comparable with the filter blank concentration, As a result, using the filter blank for correction was reasonable (see Sect. 2.2), though no field blank filter was collected during this sampling campaign.

\subsection{Positive artifact and the origin of backup OC}

The concentration of gaseous organics may be an order of magnitude higher than that of particulate OC (Mader et al., 2003; Mader and Pankow, 2003). As a result, the adsorption of gaseous organics by the bare quartz filter, or the positive 


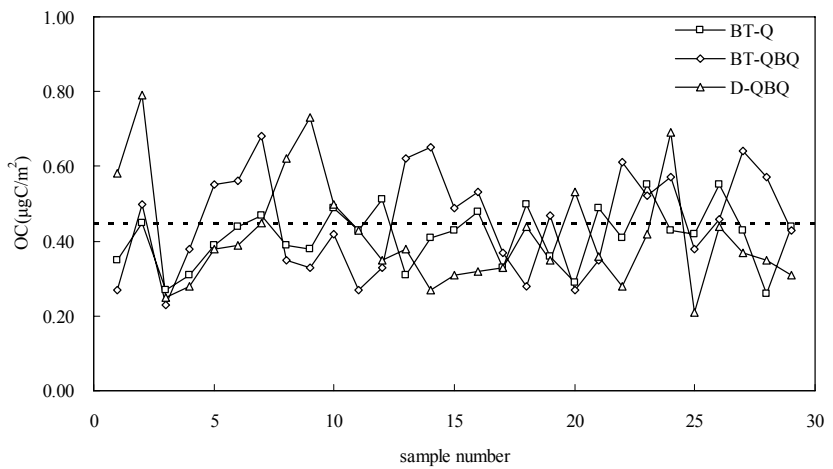

Fig. 4. OC concentrations determined by the front (BT-Q) and backup (BT-QBQ) quartz filter in the breakthrough channel, and by the denuded backup quartz filter (D-QBQ) in channel 1. Dashed line indicates average of blanks. Values not corrected by filter blank. Paired t-test showed that OC determined by BT-Q, BT-QBQ and DQBQ were not significantly different at a $95 \%$ level of confidence; and independent t-test showed they were also not significantly different from the 14 filter blank values.

artifact, could be significant. The positive artifact in Beijing during the sampling period was demonstrated in Fig. 5a. About $10 \%$ of the OC determined by bare quartz filter was from adsorbed gaseous organics. As shown in Table 2, the fraction of positive artifact in the BQ OC was more significant for low-volume sampling (Olson and Norris, 2005); the fraction was also considerable when the OC concentration was low, such as the results reported by Europe and Canadian investigators. And a substantial amount of BQ OC was from the positive artifact when the contribution of biomass burning was important (Eatough et al., 2003b).

The backup quartz approach has long been used to correct the positive artifact (Hering et al., 1990; Turpin et al., 1994), but the origin of the OC collected by the backup quartz filter (backup OC, collected by QBQ or BQT), whether from gaseous organics passing through the front filter (positive artifact-contributed) or from evaporated particulate OC (negative artifact-contributed), has been debated for years (Turpin et al., 2000). McDow and Huntzicker (1990) found a decrease in the $\mathrm{OC}$ concentration determined by the bare quartz filter with increasing face velocity, and the dependence was removed when backup OC was subtracted, thus providing indirect evidence for the origin of backup OC (positive artifactcontributed).

The application of the organic denuder provides a direct approach to quantitatively evaluate the origin of backup OC, which could provide important insights into the positive artifact problem. The approaches developed by Cheng et al. (2009) were adopted for this purpose, and were briefly described here: (1) backup OC consists of both positive artifact-contributed $\mathrm{OC}$ and negative artifact-contributed $\mathrm{OC}$, (2) OC determined by the denuded backup quartz filter, after corrected by breakthrough, provides an upper limit
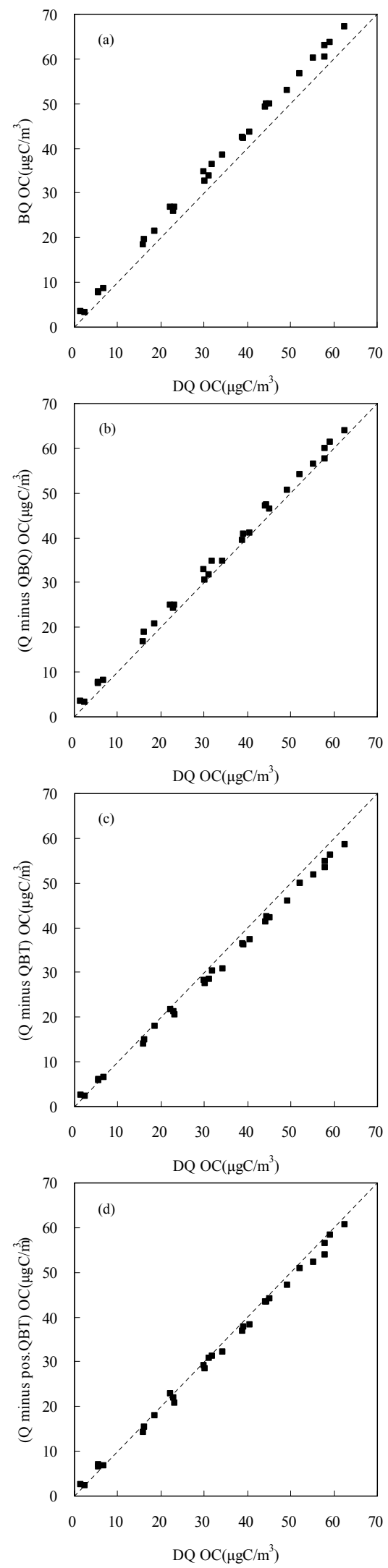

Fig. 5. Comparison of DQ OC with (a) BQ OC, (b) (Q minus QBQ) $\mathrm{OC},(\mathbf{c})(\mathrm{Q}$ minus $\mathrm{QBT}) \mathrm{OC}$, and (d) (Q minus pos.QBT) OC. 
Table 2. Average concentrations of BQ OC and DQ OC at various sampling sites. Also listed are QBQ OC and the positive artifact defined as the difference of BQ OC and DQ OC.

\begin{tabular}{|c|c|c|c|c|c|c|}
\hline Sampling site & $\begin{array}{l}\text { Sampling } \\
\text { period }\end{array}$ & $\begin{array}{l}\text { BQ } \\
\text { OC }\end{array}$ & $\begin{array}{l}\text { DQ } \\
\text { OC }\end{array}$ & $\begin{array}{l}\text { Positive } \\
\text { artifact }^{\mathrm{a}}\end{array}$ & $\begin{array}{l}\text { QBQ } \\
\mathrm{OC}^{\mathrm{b}}\end{array}$ & Reference \\
\hline Pasadena, CA & Aug 2001 & 10.89 & 9.04 & $\begin{array}{c}1.85 \\
(17 \%)\end{array}$ & 1.87 & Mader et al. $(2001)^{\mathrm{c}}$ \\
\hline Provo, UT & Aug 1996-Jan 1997 & 17.69 & 11.75 & $\begin{array}{c}5.94 \\
(34 \%)\end{array}$ & 4.10 & Ding et al. $(2002)^{\mathrm{c}}$ \\
\hline Southern Africa & Aug-Sep 2000 & 29.46 & 15.72 & $\begin{array}{l}13.74 \\
(47 \%)\end{array}$ & $\begin{array}{c}9.27 \\
(15.16)\end{array}$ & Eatough et al. $(2003 b)^{c}$ \\
\hline Toronto, Canada & July 2001 & 7.3 & 4.1 & $\begin{array}{c}3.2 \\
(44 \%)\end{array}$ & - & Fan et al. $(2003)^{\mathrm{c}}$ \\
\hline Vancouver, Canada & Aug 2001 & 3.59 & 2.50 & $\begin{array}{c}1.09 \\
(30 \%)\end{array}$ & - & Fan et al. $(2004 b)^{c}$ \\
\hline Pittsburgh, PA & Jul-Aug 2001 & 4.1 & 2.8 & $\begin{array}{c}1.3 \\
(32 \%)\end{array}$ & 0.5 & Cabada et al. $(2004)^{\mathrm{c}}$ \\
\hline Research Triangle Park, NC & - & 11.8 & 4.0 & $\begin{array}{c}7.8 \\
(66 \%)\end{array}$ & $\begin{array}{c}3.5 \\
(7.9)\end{array}$ & Olson and Norris $(2005)^{\mathrm{d}}$ \\
\hline Ghent, Belgium & Jun-Jul 2004 & 2.7 & 1.9 & $\begin{array}{c}0.8 \\
(30 \%)\end{array}$ & 0.16 & Viana et al. $(2006 a)^{d}$ \\
\hline \multirow[t]{2}{*}{ Barcelona, Spain } & Jul-Aug 2004 & 3.6 & 3.0 & $\begin{array}{c}0.6 \\
(17 \%)\end{array}$ & 0.5 & \multirow[t]{2}{*}{ Viana et al. $(2006 b)^{d}$} \\
\hline & Nov-Dec 2004 & 6.9 & 4.9 & $\begin{array}{c}2.0 \\
(29 \%)\end{array}$ & 0.7 & \\
\hline \multirow[t]{3}{*}{ Fresno, CA } & Winter, 1999-2003 & 11.76 & 10.8 & $\begin{array}{l}0.96 \\
(8 \%)\end{array}$ & $\begin{array}{l}1.28 \\
(2.10)\end{array}$ & \multirow[t]{3}{*}{ Chow et al. $(2006)^{\mathrm{d}}$} \\
\hline & Summer, 1999-2003 & 4.8 & 3.9 & $\begin{array}{c}0.9 \\
(19 \%)\end{array}$ & $\begin{array}{c}0.91 \\
(1.84)\end{array}$ & \\
\hline & 1999-2003 & 7.2 & 6.0 & $\begin{array}{c}1.2 \\
(17 \%)\end{array}$ & $\begin{array}{c}0.91 \\
(1.75)\end{array}$ & \\
\hline Beijing, China & Jan-Feb 2009 & 36.13 & 32.57 & $\begin{array}{c}3.56 \\
(9.9 \%)\end{array}$ & $\begin{array}{c}1.93 \\
(5.59)\end{array}$ & This study ${ }^{\mathrm{c}}$ \\
\hline
\end{tabular}

${ }^{a}$ Percentage of positive artifact in BQ OC in parentheses. ${ }^{\mathrm{b}}$ QBT OC in parentheses. ${ }^{\mathrm{c}}$ Values reported in $\mu \mathrm{gC} / \mathrm{m}^{3}$. ${ }^{\mathrm{d}}$ Values reported in $\mu \mathrm{g} / \mathrm{m}^{3}$.

of negative artifact-contributed OC, since the removal of gaseous organics enhances the evaporation of particulate organic carbon, (3) thus, the positive artifact-contributed OC is calculated as the difference between backup OC and negative artifact-contributed OC.

\subsubsection{Evaluation of QBQ OC as estimation for positive artifact}

As shown in Fig. 4, OC determined by the denuded backup quartz filter in channel 1, D-QBQ, was comparable with blank values, indicating that no evaporated OC was collected. Negligible amount of OC on denuded backup quartz filter (behind front quartz filter) was also reported by Mader et al. (2001), Ding et al. (2002), and Viana et al. (2006). This may be caused by two factors: (1) a fraction of evaporated
OC was re-adsorbed by the front quartz filter (Eatough et al., 2003b; Subramanian et al., 2004); (2) the evaporated OC has a low affinity to quartz filter. Viana et al. (2007) stated that DQ $\mathrm{OC} \approx 0$ could be used as indication of the capacity of the organic denuder for eliminating the positive artifact. As a result, all the OC collected by the backup quartz filter in channel 3, QBQ OC, was from gaseous organics passing through the front filter, or positive artifact-contributed. Therefore using QBQ OC to correct the positive artifact was reasonable.

The remaining concern was whether the backup quartz filter (QBQ) adsorbed the same amount of gaseous organics as the front filter (BQ), in other words, whether both the front and backup filter were saturated or reached equilibrium with gaseous organics. The gaseous organics adsorbed by BQ could be estimated as (BQ-DQ) OC. As shown in Figs. 6, 7, and Table 3, no evidence for saturation was seen. 
Table 3. Results of the statistical analysis of the Beijing $\mathrm{PM}_{2.5}$ OC/EC data.

\begin{tabular}{lllllll}
\hline X versus Y & $n$ & $R^{2}$ & Slope & Intercept & X average & Y average \\
\hline DQ OC versus BQ OC $^{\mathrm{a}}$ & 29 & 0.9952 & 1.094 & 0 & 32.57 & 36.13 \\
& & 0.9980 & 1.045 & 2.09 & & \\
DQ OC versus (Q minus QBQ) OC & 29 & 0.9954 & 1.037 & 0 & 32.57 & 34.20 \\
& & 0.9977 & 0.995 & 1.79 & & \\
DQ OC versus (Q minus QBT) OC $^{\mathrm{a}}$ & 29 & 0.9985 & 0.937 & 0 & 32.57 & 30.54 \\
& & 0.9985 & 0.933 & 0.14 & & \\
DQ OC versus (Q minus pos.QBT) OC $^{\mathrm{a}}$ & 29 & 0.9974 & 0.965 & 0 & 32.57 & 31.52 \\
& & 0.9975 & 0.955 & 0.41 & & \\
BQ OC versus QBQ OC $^{\mathrm{a}}$ & 29 & 0.7396 & 0.052 & 0 & 36.13 & 1.93 \\
& & 0.7463 & 0.048 & 0.19 & & \\
BQ OC versus QBT OC $^{\mathrm{a}}$ & 29 & 0.7423 & 0.145 & 0 & 36.13 & 5.59 \\
& & 0.8665 & 0.108 & 1.68 & & \\
ECcal versus TOT-split-EC (denuded) $^{\mathrm{b}, \mathrm{c}}$ & 10 & 0.9848 & 0.788 & 0 & 4.00 & 2.79 \\
ECcal versus TOT-split-EC (un-denuded) $^{\mathrm{b}, \mathrm{c}}$ & 10 & 0.9882 & 0.716 & 0 & 4.05 & 2.86 \\
PC (un-denuded) versus PC (denuded) $^{\mathrm{b}, \mathrm{c}}$ & 29 & 0.9537 & 0.934 & 0 & 8.11 & 7.51 \\
\hline
\end{tabular}

${ }^{\mathrm{a}}$ Average values reported in $\mu \mathrm{gC} / \mathrm{m}^{3} .{ }^{\mathrm{b}}$ Average values reported in $\mu \mathrm{gC} / \mathrm{cm}^{2} .{ }^{\mathrm{c}}$ Values not corrected by filter blank.

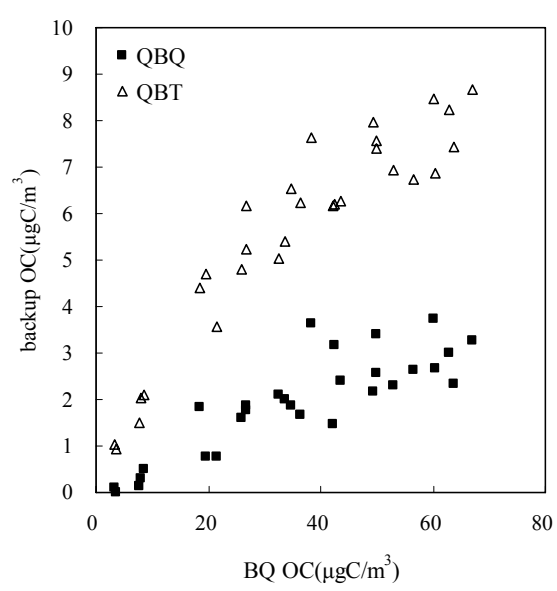

Fig. 6. Comparison of BQ OC and different estimations of backup OC (QBQ OC and QBT OC).

Linear regression analysis showed that $(\mathrm{Q}-\mathrm{QBQ}) \mathrm{OC}$ and DQ OC correlated well and showed a remarkable fit with an almost 1:1 correspondence expect for a positive intercept of $1.79 \mu \mathrm{gC} / \mathrm{m}^{3}$ (Fig. 5b and Table 3), indicating that the difference between (Q-QBQ) OC and DQ OC was constant regardless their absolute concentrations. The most likely explanation for the stable difference was that the backup quartz filter had not reach equilibrium with the gaseous organics, due to the relatively small sampling volume (typically $9.3 \mathrm{~m}^{3}$ ). Kirchstetter et al. (2001) found that the QBQ OC was a reasonable measurement of the positive artifact with a $14 \mathrm{~h}$ sample (corresponding to a sampling volume of $25 \mathrm{~m}^{3}$ ) rather than with samples of 2,4 , or $8 \mathrm{~h}$ duration when sampling at a flow rate of $30 \mathrm{~L} / \mathrm{min}$. According to the results reported by Subramanian et al. (2004), (Q-QBQ) OC was almost the same as the sum of NVOC (DQ OC) and SVOC (determined by CIG, corrected by breakthrough), indicating QBQ OC underestimated the positive artifact even for a sampling volume of $24 \mathrm{~m}^{3}(16.7 \mathrm{~L} / \mathrm{min}, 24 \mathrm{~h}$ samples).

Most of the results in Table 2 showed that the positive artifact was underestimated by QBQ OC, except that from Mader et al. (2001). Data reported by Mader et al. (2001) were re-interpreted, and result of linear regression analysis showed that BQ OC and DQ OC (no breakthrough was detected) correlated well $\left(R^{2}=0.9848\right)$ with a slope of 1.00 and a positive intercept of $1.82 \mu \mathrm{gC} / \mathrm{m}^{3}$. A similar result (a slope of 0.98 and an intercept of $0.53 \mu \mathrm{gC} / \mathrm{m}^{3}$ ) was reported by Subramanian et al. (2004), who suggested that the almost 1 slope and positive intercept indicate the equilibrium of the bare quartz filter with gas phase. As a result, one possible explanation for the overestimation of positive artifact by QBQ OC (data reported by Mader et al., 2001) was that the adsorption capacity of the loaded quartz filter (BQ) was reduced by the particles, compared with the backup filter without particle loading (QBQ). It should be pointed out that the adsorption of gaseous organics on collected particles is unlikely to be important for a loaded filter, since the collected particles are presumably in equilibrium with the gas phase at the time of collection and the surface area of the collected particles is small relative to that of the quartz filter (McDow and Huntzicker, 1990). If this hypothesis were true, once the front quartz filter reached equilibrium with gas phase, there was the possibility that the backup quartz filter (QBQ) adsorbed more gaseous organics than the front one. 
According to the statement of Subramanian et al. (2004), it seemed that even the bare quartz filter had not reached equilibrium (Table 3), indicating this was the case for the QBQ filter, since the front filter always reaches equilibrium before the backup one (Mader and Pankow, 2003). Then it could be conclude that, though all the QBQ OC was from gaseous organics passing through the front filter, the QBQ adsorbed less gaseous organics than the front one (Fig. 7) and thus undercorrected the positive artifact by $3.7 \%$. (Fig. $5 \mathrm{~b}$ and Table 3).

\subsubsection{Evaluation of QBT OC as estimation for positive artifact}

A substantial amount of OC was determined by the denuded backup quartz filter in channel 2, D-QBT OC, which was the negative artifact-contributed OC. The amount of positive artifact-contributed OC was obtained by subtracting D-QBT OC from the OC collected by the backup quartz filter in channel 4, QBT OC. $82 \%$ and $18 \%$ of QBT-OC was the average positive and negative artifact contribution. As a result, QBT OC overcorrected the positive artifact (by 6.3\%, Fig. 5c and Table 3), consistent with the results shown in Table 2.

Backup quartz behind Teflon filter is usually assumed to be exposed to the same gaseous organics concentrations as the bare quartz (Turpin et al., 1994; Mader and Pankow, 2003). As a result, it was with expectation that the positive artifactcontributed QBT OC was higher than QBQ OC, considering QBQ adsorbed less gaseous organics than the front one (Fig. 7).

It was noticed that the positive artifact-contributed QBT OC overestimated the positive artifact which was defined as the difference between BQ OC and DQ OC (Figs. 5d and 7). The overestimation provided an evidence for the hypothesis that the adsorption capacity of the loaded filter was lower compared to the filter without particle loading, as discussed in Sect. 3.2.1.

To our knowledge, few studies have focused on the denuded QBT, and this was the first time that positive and negative artifact-contributed QBT OC was quantitatively determined. As a result, the difference between positive artifactcontributed QBT OC and (BQ-DQ) OC is still not well understood and further research is needed.

\subsection{Influence of positive artifact on partitioning of PC and $\mathrm{EC}$}

The multiple linear regression approach developed by Chow et al. (2004) was used for the re-partitioning of PC and EC, and was briefly described here. The calculation was based on the attenuation coefficient $(k)$ which was defined as:

$k=\frac{-\ln \left(I_{i} / I_{f}\right)}{C}$

where $I_{i}$ and $I_{f}$ were the initial and final laser transmission through the loaded filter for the portion of the analysis of in-

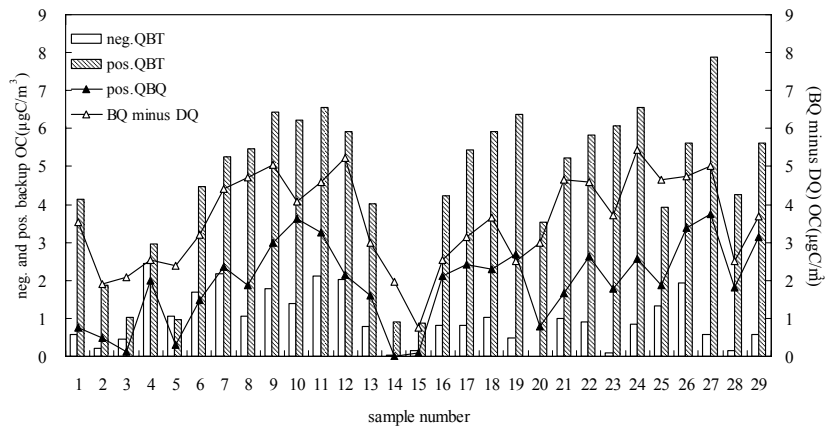

Fig. 7. Negative artifact-contributed QBT OC (neg.QBT), and different estimations of positive artifact: positive artifactcontributed QBT OC (pos.QBT), positive artifact-contributed QBQ OC (pos.QBQ), and the difference between BQ and DQ ((BQ minus DQ) OC).

terest, and $C$ was the mass of carbon per unit filter area that was evolved from the filter during the analysis segment (Subramanian et al., 2006). It was then assumed that the carbon that evolved in the $\mathrm{He}-\mathrm{O}_{2}$ mode $\left([\text { carbon }]_{\mathrm{He}-\mathrm{O}_{2}}\right.$ ) contained only EC and PC, and as a result the increase of the transmission signal in the $\mathrm{He}-\mathrm{O}_{2}$ mode was contributed by the evolution of EC and PC. Thus, ([carbon $]_{\mathrm{He}-\mathrm{O}_{2}}$ ) could be estimated as:

$$
\begin{aligned}
\text { [carbon] }]_{\mathrm{He}-\mathrm{O}_{2}} & =\mathrm{EC}+\mathrm{PC} \\
& =\frac{-\ln \left(I_{i} / I_{f}\right)}{k_{\mathrm{EC}}}+\frac{-\ln \left(I_{\min } / I_{f}\right)-\left(-\ln \left(I_{i} / I_{f}\right)\right)}{k_{\mathrm{PC}}} \\
& =\frac{-\ln \left(I_{i} / I_{f}\right)}{k_{\mathrm{EC}}}+\frac{-\ln \left(I_{\min } / I_{i}\right)}{k_{\mathrm{PC}}}
\end{aligned}
$$

where $I_{i}, I_{f}$ was the transmission at the beginning and end of the analysis respectively, $I_{\min }$ was the minimum of transmission signal; $k_{\mathrm{EC}}$ and $k_{\mathrm{PC}}$ was the attenuation coefficient of EC and PC respectively; $-\ln \left(I_{i} / I_{f}\right)$ was the attenuation caused by $\mathrm{EC}$, and $-\ln \left(I_{\min } / I_{f}\right)$ was the attenuation caused by EC and PC. Thus the attenuation caused by PC was estimated as the difference between $-\ln \left(I_{\min } / I_{f}\right)$ and $-\ln \left(I_{i} / I_{f}\right)$, or $-\ln \left(I_{\min } / I_{i}\right)$. Then a multiple linear regression of the [carbon $]_{\mathrm{He}-\mathrm{O}_{2}}$ on $-\ln \left(I_{i} / I_{f}\right)$ and $-\ln \left(I_{\min } / I_{i}\right)$ could yield estimations of the inverse attenuation coefficients of EC and PC. There were three preconditions for this calculation. The first was the flattening of the carbon signal at the end of each temperature plateau, since the $1 \mathrm{~s}$-average carbon concentration determined by the flame ionization detector (FID) does not have a one-to-one correspondence to the optical measurements (due to a tailing effect caused by transit through $\mathrm{C}$ to $\mathrm{CO}_{2}$ and $\mathrm{CO}_{2}$ to $\mathrm{CH}_{4}$ ). The second was the transmission signal should reach its minimum value in the last step of the He mode and should not increase until the introduction of $\mathrm{O}_{2}$, to guarantee that the PC was fully formed and there was no premature evolution of EC and PC. The third was that the minimum transmission should be detectable (at the end of He mode). These conditions were met for 10 of the 29 sets of samples (10 denuded and 10 undenuded samples, respectively). 
The attenuation coefficients of EC and PC calculated by the 10 sets of denuded and un-denuded samples were $18.83,38.64$ and $18.12,45.56 \mathrm{~m}^{2} / \mathrm{g}$, respectively. The zerointercept correlation $\left(R^{2}\right)$ of the multiple linear regression were 0.996 and 0.992 , for the denuded and un-denuded samples, respectively. It was consistent with other studies that $k_{\mathrm{PC}}$ was higher than $k_{\mathrm{EC}}$ (Chow et al., 2004; Subramanian et al., 2006), indicating PC formed in the He mode was darker than native EC, which would result in an underestimation of native EC by the TOT-split-EC (due to the coevolution of $\mathrm{PC}$ and $\mathrm{EC}$ ). $k_{\mathrm{EC}}$ were comparable for the denuded and un-denuded samples, and were also comparable with the $18.5 \mathrm{~m}^{2} / \mathrm{g}$ reported by Chow et al. (2004). $k_{\mathrm{PC}}$ calculated by the un-denuded samples was comparable with the $48.5 \mathrm{~m}^{2} / \mathrm{g}$ reported by Chow et al. (2004), but higher than that calculated from the denuded samples, indicating the PC formed on the un-denuded filter was darker than that formed on the denuded filter.

The re-partitioning of EC and PC was finally completed by Eq. (3), and the result was shown in Fig. 8.

$\mathrm{EC}_{\mathrm{cal}}=\frac{-\ln \left(I_{i} / I_{f}\right)}{k_{\mathrm{EC}}}, \quad \mathrm{PC}_{\mathrm{cal}}=[\text { carbon }]_{\mathrm{He}-\mathrm{O}_{2}}-\mathrm{EC}_{\mathrm{cal}}$

As shown in Fig. 8 and Table 3, TOT-split-EC underestimated native EC by $21 \%$ and $28 \%$, for denuded and undenuded samples, respectively. The underestimation for the un-denuded samples was more significant, since the PC formed on it was darker.

\subsection{Influence of positive artifact on formation of PC}

TOT-split-PC was compared in Table 3 for denuded and undenuded samples. Formation of PC was reduced by $7 \%$ after removal of the positive artifact. Considering that the positive artifact contributed $10 \%$ of BQ OC, the PC formation potential of gaseous organics adsorbed on the quartz filter should be comparable with that of particulate organic carbon. As a result, removal of the positive artifact did not have a significantly influence on PC formation.

\section{Conclusions}

Capacity of the activated carbon denuder for the removal of gaseous organics that could be adsorbed on the quartz filter was demonstrated during a sampling period of about a month in Beijing. Comparison of BQ OC and DQ OC showed that about $10 \%$ of the OC determined by the bare quartz filter was from the positive artifact. Negligible amount of OC was detected on the denuded backup quartz filter, indicating the amount of evaporated OC (that could be adsorbed by the quartz filter) was minimal.

The backup quartz approach was evaluated for estimating the positive artifact. $100 \%$ of the QBQ OC was from gaseous organics passing through the front filter, or from the positive
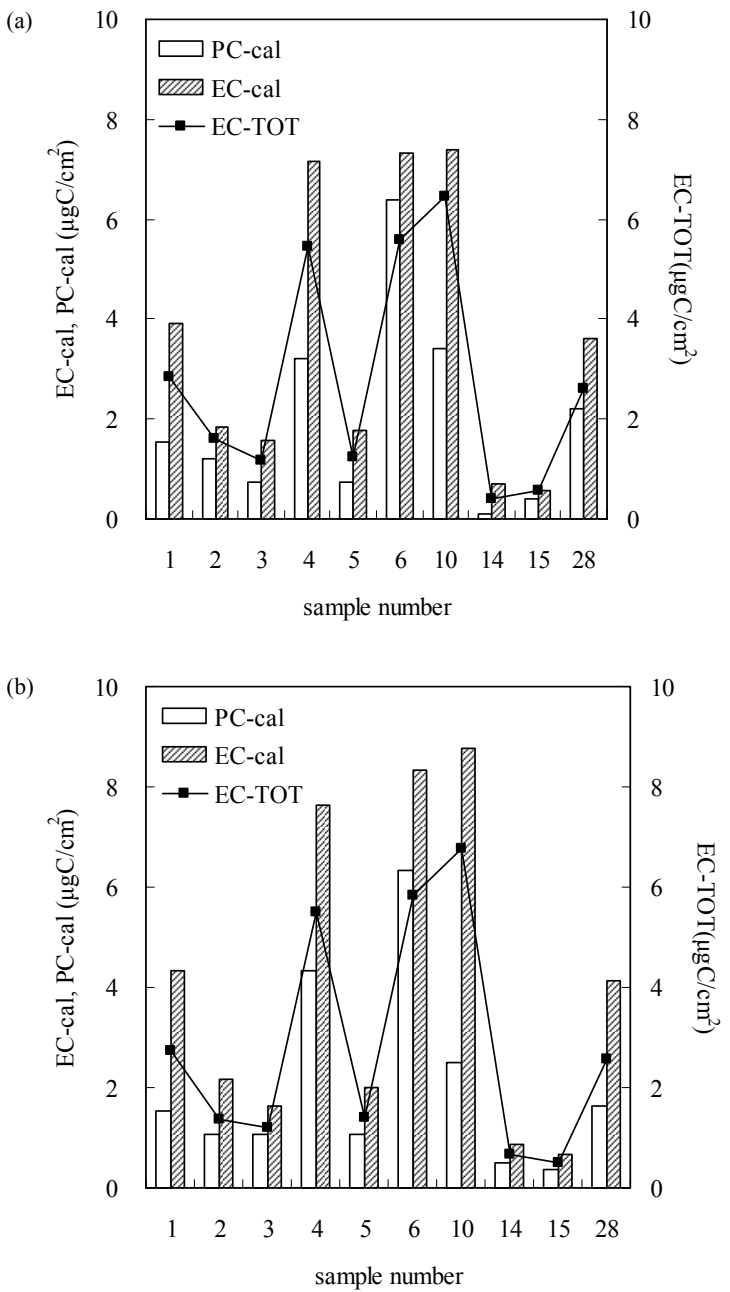

Fig. 8. Comparison of calculated EC concentration (EC-cal) and TOT-split-EC (EC-TOT) for (a) denuded samples, and (b) undenuded samples. Calculated PC concentration (PC-cal) is also shown. Values not corrected by filter blank.

artifact. Due to the relatively small sampling volume, the QBQ had not reached equilibrium with gas phase, and as a result, underestimated the positive artifact by $3.7 \%$. QBT OC consisted of both gaseous organics passing through the front filter $(82 \%)$ and evaporated particulate OC $(18 \%)$, thus QBT OC overestimated the positive artifact by $6.3 \%$. In addition, it was found that the positive artifact-contributed QBT OC overestimated the positive artifact by $3.5 \%$. This may be caused by the difference in the adsorption properties of the loaded filter and the filter without particle loading. Further research is needed to give a deeper insight into this overestimation.

Re-partitioning of PC and EC was performed based on the attenuation coefficient. It was with expectation that PC was darker than EC. Moreover, it was found that PC formed on the bare quartz filter was darker than that formed on the denuded filter. As a result, TOT-split-EC underestimated 
native EC by $21 \%$ and $28 \%$, for denuded and un-denuded samples, respectively. It was also shown that the PC formation potential of gaseous organics adsorbed on the quartz filter was comparable with that of particulate organic carbon, indicating that removing of the positive artifact did not influence the PC formation significantly. As a result, though the PC formed on the denuded filter was lighter in color, the application of the organic denuder did not completely solve the problems of split of OC/EC, which was caused by the difference in the attenuation coefficient of EC and PC.

\section{Discussion}

Both the integrated sampler used in the monitoring network and the more recently developed semi-continuous equipment are challenged to accurately measure carbonaceous aerosols, including the positive and negative artifact, and the split of OC/EC. The organic denuder is effective at eliminating the positive artifact and it is the precondition for the determination of the negative artifact, or the semivolatile organic carbon. More attention should be paid to semivolatile organic carbon in the future (Fig. 1), considering its secondary nature (Modey et al., 2004; Eatough et al., 2006), and its influence on regional haze (Long et al., 2005). Calculation of the attenuation coefficient of EC and PC is essential for the accurate split of OC and $\mathrm{EC}$, based on the current thermal-optical method. This is especially meaningful for China, due to its high EC emission (Zhang et al., 2007). Moreover, attenuation of EC is an important optical parameter for determining the impact of particulate matter on visibility and climate change. The multiple linear regression approach developed by Chow et al. (2004) is more convenient for this purpose compared with the solvent extraction method used by Subramanian et al. (2006). But there maybe some potential artifacts for both approaches, such as the influence of stray light on the measured laser signal, especially at lower transmittance levels. The stray light could not be avoided even by the best instrument. It is a substantial challenge for the current thermal-optical equipments that how to quantitatively determine the influence of stray light and how to eliminate or minimize it. Finally, more efforts should be made to improve the measurement of carbonaceous aerosols, while at the same time developing monitoring networks and new monitoring equipment.

Acknowledgements. This work was supported by the National Natural Science Foundation of China through grant number 20625722 to He Kebin, and by the Foundation for the Author of National Excellent Doctoral Dissertation of PR China (2007B57). The authors would like to acknowledge visiting scholar Charles N. Freed for revising the paper. The authors would also like to acknowledge Chen Lai-guo in South China Institute of Environmental Science, MEP for his help in the OC/EC analysis.
Edited by: T. Kirchstetter

\section{References}

Andreae, M. O. and Gelencsér, A.: Black carbon or brown carbon? The nature of light-absorbing carbonaceous aerosols, Atmos. Chem. Phys., 6, 3131-3148, 2006, http://www.atmos-chem-phys.net/6/3131/2006/.

Cabada, J. C., Pandis, S. N., Subramanian, R., Robinson, A. L., Polidori, A., and Turpin, B.: Estimating the Secondary Organic Aerosol Contribution to PM2.5 Using the EC Tracer Method, Aerosol Sci. Tech., 38, 140-155, 2004.

Chan, C. K. and Yao, X. H.: Air pollution in mega cities in China, Atmos. Environ., 42, 1-42, 2009.

Cheng, Y., He, K. B., Duan, F. K., Zheng, M., Ma, Y. L., and Tan, J. H.: Measurement of semivolatile carbonaceous aerosols and its implications: a review, Environ. Int., 35, 674-681, 2009.

Chow, J. C., Watson, J. G., Crow, D., Lowenthal, D. H., and Merrifield, T.: Comparison of IMPROVE and NIOSH carbon measurements, Aerosol Sci. Tech., 34, 23-34, 2001.

Chow, J. C., Watson, J. G., Chen, L. A., Arnott, W. P., and Moosmüller, H.: Equivalence of elemental carbon by thermal/optical reflectance and transmittance with different temperature protocols, Environ. Sci. Tech., 38, 4414-4422, 2004.

Chow, J. C., Watson, J. G., Louie, P. K. K., Chen, L. A., and Sin, D.: Comparison of PM2.5 carbon measurement methods in Hong Kong, China, Environ. Pollut., 137, 334-344, 2005 a.

Chow, J. C., Watson, J. G., Chen, L.-W. A., Paredes-Miranda, G., Chang, M.-C. O., Trimble, D., Fung, K. K., Zhang, H., and Zhen Yu, J.: Refining temperature measures in thermal/optical carbon analysis, Atmos. Chem. Phys., 5, 2961-2972, 2005b, http://www.atmos-chem-phys.net/5/2961/2005/.

Chow, J. C., Watson, J. G., Lowenthal, D. H., Chen, L. A., and Magliano, K. L.: Particulate carbon measurements in California's San Joaquin Valley, Chemosphere, 62, 337-348, 2006.

Chow, J. C., Watson, J. G., Chen, L. A., Chang, M. O., Robinson, N. F., Trimble, D., and Kohl, S.: The IMPROVE-A temperature protocol for thermal/optical carbon analysis: maintaining consistency with a long-term database, J. Air Waste Manage., 57, 1014-1023, 2007.

Chow, J. C., Doraiswamy, P., Waston, J. G., Chen, L. A., Ho, S. S. H., and Sodeman, D. A.: Advances in integrated and continuous measurements for particle mass and chemical composition, J. Air Waste Manage., 58, 141-163, 2008.

Conny, J. M., Klinedinst, D. B., Wight, S. A., and Paulsen, J. L.: Optimizing thermal-optical methods for measuring atmospheric elemental (black) carbon: a response surface study, Aerosol Sci. Tech.., 37, 703-723, 2003.

Ding, Y. M., Pang, Y. B., and Eatough, D. J.: High-volume diffusion denuder sampler for the routine monitoring of fine particulate matter: I. design and optimization of the PC-BOSS, Aerosol Sci. Tech.., 36, 369-382, 2002.

Eatough, D. J., Wadsworth, A., Eatough, D. A., Crawford, J. W., Hansen, L. D., and Lewis, E. A.: A multiple-system, multichannel diffusion denuder sampler for the determination of fineparticulate organic material in the atmosphere, Atmos. Environ., 27A, 1213-1219, 1993. 
Eatough, D. J., Obeidi, F., Pang, Y. B., Ding, Y. M., Eatough, N. L., and Wilson, W. E.: Integrated and real-time diffusion denuder sampler for PM2.5, Atmos. Environ., 33, 2835-2844, 1999.

Eatough, D. J., Eatough, N. L., Obeidi, F., Pang, Y. B., Modey, W., and Long, R.: Continuous determination of PM2.5 mass, including semi-volatile species, Aerosol Sci. Tech., 34, 1-8, 2001.

Eatough, D. J., Long, R. W., Modey, W. K., and Eatough, N. L.: Semi-volatile secondary organic aerosol in urban atmospheres: meeting a measurement challenge, Atmos. Environ, 37, 12771292, 2003a.

Eatough, D. J., Eatough, N. L., Pang, Y., Sizemore, S., Kirchstetter, T. W., Novakov, T., and Hobbs, P. V.:. Semivolatile particulate organic material in southern Africa during SAFARI 2000, J. Geophys. Res., 108(D13), 8479, doi:10.1029/2002JD002296, 2003b.

Eatough, D. J., Anderson, R. R., Martello, D. V., Modey, W. K., and Mangelson, N. F.: Apportionment of Ambient Primary and Secondary PM2.5 During a 2001 Summer Intensive Study at the NETL Pittsburgh Site Using PMF2 and EPA UNMIX, Aerosol Sci. Tech., 40, 925-940, 2006.

Eiguren-Fernandez, A., Miguel, A. H., Jaques, P. A., and Sioutas, C.: Evaluation of a denuder-MOUDI-PUF sampling system to measure the size distribution of semi-volatile polycyclic aromatic hydrocarbons in the atmosphere, Aerosol Sci. Tech., 37, 210209, 2004.

Fan, X. H., Brook, J., and Mabury, S. A.: Sampling atmospheric carbonaceous aerosols using an integrated organic gas and particulate sampler, Environ. Sci. Technol., 37, 3145-3151, 2003.

Fan, X. H., Lee, P. K. H., Brook, J. R., and Mabury, S. A.: Improved measurement of seasonal and diurnal differences in the carbonaceous components of urban particulate matter using a denuderbased air sampler, Aerosol Sci. Tech., 38, 63-69, 2004a.

Fan, X. H., Brook, J. R., and Mabury, S. A.: Measurement of organic and elemental carbon associated with PM2.5 during Pacific 2001 study using an integrated organic gas and particle sampler, Atmos. Environ., 38, 5801-5810, 2004b.

Fung, K.: Particulate carbon speciation by $\mathrm{MnO} 2$ oxidation, Aerosol Sci. Tech., 12, 122-127, 1990

Goriaux, M., Jourdain, B., Temime, B., Besombes, J. L., Marchand, N., Albinet, A., Leoz-Garziandia, E., and Wortham, H.: Field comparison of particulate PAH measurements using a low-flow denuder device and conventional sampling systems, Environ. Sci. Technol., 40, 6398-6404, 2006.

Guinot, B., Cachier, H., Sciare, J., Yu, T., Wang, X., and Yu, J. H.: Beijing aerosol: atmospheric interactions and new trends, J. Geophys. Res., 112, D14314, doi:10.1029/2006JD008195, 2007.

Gundel, L. A., Lee, V. C., Mahanama, K. R. R., Stevens, R. K., and Daisey, J. M.: Direct determination of the phase distributions of semi-volatile polycyclic aromatic hydrocarbons using annular denuders, Atmos. Environ., 29, 1719-1733, 1995a.

Gundel, L. A., Mahanama, K. R. R., and Daisey, J. M.: Semivolatile and particulate polycyclic aromatic hydrocarbons in environmental tobacco smoke: cleanup, speciation, and emission factors, Environ. Sci. Technol., 29, 1607-1614, 1995b.

He, K. B., Yang, F. M., Ma, Y. L., Zhang, Q., Yao, X. H., Chan, C. K., Cadle, S., Chan, T., and Mulawa, P.: The characteristics of PM2.5 in Beijing, China, Atmos. Environ., 35, 4959-4970, 2001.

Hering, S. V., Appel, B. R., Cheng, W., Salaymeh, F., Cadle, S. H.,
Mulawa, P. A., Cahill, T. A., Eldred, R. A., Surovik, M., Fitz, D., Howes, J. E., Knapp, K. T., Stockburger, L., Turpin, B. J., Huntzicker, J. J., Zhang, X. Q., and McMurry, P. H.: Comparison of sampling methods for carbonaceous aerosols in ambient air, Aerosol Sci. Technol., 12, 200-213, 1990.

Huang, X.-F. and Yu, J. Z.: Size distributions of elemental carbon in the atmosphere of a coastal urban area in South China: characteristics, evolution processes, and implications for the mixing state, Atmos. Chem. Phys., 8, 5843-5853, 2008, http://www.atmos-chem-phys.net/8/5843/2008/.

Huebert, B. J. and Charlson, R. J.: Uncertainties in data on organic aerosols, Tellus B, 52, 1249-1255, 2000.

Huntzicker, J. J., Johnson, R. L., Shah, J. J., and Cary, R. A.: Analysis of organic and elemental carbon in ambient aerosols by a thermal-optical method, in: Particulate carbon: Atmospheric life cycle, Plenum Press, New York, 79-88, 1982.

Jacobson, M. C., Hansson, H. C., Noone, K. J., and Charlson, R. J.: Organic atmospheric aerosols: review and state of the science, Rev. Geophys., 38, 267-294, 2000.

Kamens, R. M. and Coe, D. L.: A large gas-phase stripping device to investigate rates of PAH evaporation from airborne diesel soot particles, Environ. Sci. Technol., 31, 1830-1833, 1997.

Kirchstetter, T. W., Corrigan, C. E., and Novakov, T.: Laboratory and field investigation of the adsorption of gaseous organic compounds onto quartz filters, Atmos. Environ., 35, 1663-1671, 2001.

Lane, D. A., Peters, A. J., Gundel, L. A., Jones, K. C., and Northcott, G. L.: Gas/particle partition measurement of PAH at the Hazelrigg, UK, Polycyclic Aromatic Compounds, 20, 225-234, 2000.

Long, R. W., Modey, W. K., Smith, P. S., Smith, R., Merrill, C., Pratt, J., Stubbs, A., Eatough, N. L., Eatough, D. J., Malm, W. C., and Wilson, W. E.: One- and three-hour PM2.5 characterization, speciation, and source apportionment using continuous and integrated samplers, Aerosol Sci. Tech., 39, 238-248, 2005.

Mader, B. T., Flagan, R. C., and Seinfeld, J. H.: Sampling atmospheric carbonaceous aerosols using a particle trap impactor/denuder sampler, Environ. Sci. Technol., 35, 4857-4867, 2001.

Mader, B. T., Schauer, J. J., Seinfeld, J. H., Flagan, R. C., Yu, J. Z., Yang, H., Lim, Ho-Jin, Turpin, B. J., Deminter, J. T., Heidemann, G., Bae, M. S., Quinn, P., Bates, T., Eatough, D. J., Huebert, B. J., Bertram, T., and Howell, S.: Sampling methods used for the collection of particle-phase organic and elemental carbon during ACE-Asia, Atmos. Environ., 37, 1435-1449, 2003.

Mader, B. T. and Pankow, J. F.: Gas/solid partitioning of semivolatile organic compounds (SOCs) to air filters. 3. an analysis of gas adsorption artifacts in measurements of atmospheric SOCs and organic carbon (OC) when using Teflon membrane filters and quartz fiber filters, Environ. Sci. Technol., 35, 34223432, 2003.

McDow, S. R. and Huntzicker, J. J.: Vapor adsorption artifact in the sampling of organic aerosol: face velocity effects, Atmos. Environ., 24A, 2563-2571, 1990.

Modey, W. K., Pang, Y. B., Eatough, N. L., and Eatough, D. J.: Fine particulate (PM2.5) composition in Atlanta, USA: assessment of the particle concentrator-Brigham Young University organic sampling system, PC-BOSS, during the EPA supersite study, Atmos. Environ., 35, 6493-6502, 2001. 
Modey, W. K., Eatough, D. J., Anderson, R. R., Martello, D. V., Takahama, S., Lucas, L. J., and Davidson, C. I.: Ambient fine particulate concentrations and chemical composition at two sampling sites in metropolitan Pittsburgh: a 2001 intensive summer study, Atmos. Environ., 38, 3165-3178, 2004.

Mikuška, P., Večeřa, Z., Broškovičová, A., Štěpán, M., Chi, X., and Maenhaut, W.: Development of a diffusion denuder for the elimination of sampling artifacts for carbonaceous aerosols, J. Aerosol Sci., Abstract of the European Aerosol Conference 2003, S761S762, 2003.

Novakov, T.: Soot in the atmosphere, in: Particulate carbon: Atmospheric Life Cycle, Plenum Press, New York, 19-41, 1982.

Olson, D. A. and Norris, G. A.: Sampling artifacts in measurement of elemental and organic carbon: Low-volume sampling in indoor and outdoor environments, Atmos. Environ., 39, 54375445, 2005.

Ortiz, R., Hagino, H., Sekiguchi, K., Wang, Q., and Sakamoto, K.: Ambient air measurements of six bifunctional carbonyls in a suburban area, Atmos. Res., 82, 709-718, 2006.

Ortiz, R., Enya, K., Sekiguchi, K., and Sakamoto, K.: Experimental testing of an annular denuder and filter system on measure gasparticle partitioning of semivolatile bifunctional carbonyls in the atmosphere, Atmos. Environ., 43, 382-388, 2009.

Pang, Y. B., Eatough, N. L., and Eatough, D. J.: PM2.5 Semivolatile organic material at Riverside, California: implications for the PM2.5 Federal Reference Method sampler, Aerosol Sci. Tech., 36, 277-288, 2002a.

Pang, Y. B., Eatough, N. L., Wilson, J., and Eatough, D. J.: Effect of semivolatile material on PM2.5 measurement by the PM2.5 federal reference method sampler at Bakersfield, California, Aerosol Sci. Tech., 36, 289-299, 2002b.

Peters, A. J., Lane, D. A., Gundel, L. A., Northcott, G. L., and Jones, K. C.: A comparison of high volume and diffusion denuder samplers for measuring semivolatile organic compounds in the atmosphere, Environ. Sci. Technol., 34, 5001-5006, 2000.

Peters, T. M., Gussman, R. A., Kenny, L. C., and Vanderpool, W.: Evaluation of PM2.5 size selectors used in speciation samplers, Aerosol Sci. Tech., 34, 422-429, 2001.

Reisinger, P., Wonaschütz, A., Hitzenberger, R., Petzold, A., Bauer, H., Jankowski, N., Puxbaum, H., Chi, X., and Maenhaut, M.: Intercomparison of measurement techniques for black or elemental carbon under urban background conditions in wintertime: influence of biomass combustion, Environ. Sci. Technol., 42, 884889, 2008.

Schauer, J. J., Mader, B. T., DeMinter, J. T., Heidemann, G., Bae, M. S., Seinfeld, J. H., Flagan, R, C., Cary, R. A., Smith, D., Huebert, B. J., Bertram, T., Howell, S., Kline, J. T., Quinn, P., Bates, T., Turpin, B., Lim, H. J., Yu, J. Z., Yang, H., and Keywood, M. D.: ACE-Asia intercomparison of a thermal-optical method for the determination of particle-phase organic and elemental carbon, Environ. Sci. Technol., 37, 993-1001, 2003.

Sciare, J., Cachier, H., Oikonomou, K., Ausset, P., Sarda-Estève, R., and Mihalopoulos, N.: Characterization of carbonaceous aerosols during the MINOS campaign in Crete, July-August 2001: a multi-analytical approach, Atmos. Chem. Phys., 3, 1743-1757, 2003, http://www.atmos-chem-phys.net/3/1743/2003/.

Sciare, J., Cachier, H., Sarda-Estève, R., Yu, T., and Wang, X.: Semi-volatile aerosols in Beijing (R. P. China): characterization and influence on various PM2.5 measurements, J. Geophys. Res., 112, D18202, doi:10.1029/2006JD007448, 2007.

Solomon, P., Baumann, K., Edgerton, E., Tanner, R., Eatough, D., Modey, W., Maring, H., Savoie, D., Natarajan, S., Meyer, M. B., and Norris, G.: Comparison of integrated samplers for mass and composition during the 1999 Atlanta Supersites project, J. Geophys. Res., 108(D7), 8423, doi:10.1029/2001JD001218, 2003.

Strommen, M. R. and Kamens, R. M.: Simulation of semivolatile organic compound microtransport at different times scales in airborne diesel soot particles, Environ. Sci. Technol., 33, 17381746, 1999.

Subramanian, R., Khlystov, A. Y., Cabada, J. C., and Robinson, A. L.: Positive and negative artifacts in particulate organic carbon measurement with denuded and undenuded sampler configurations, Aerosol Sci. Tech., 38, 27-48, 2004.

Subramanian, R., Khlystov, A. Y., and Robinson, A. L.: Effect of peak inert-mode temperature on elemental carbon measured using thermal-optical analysis, Aerosol Sci. Tech., 40, 763-780, 2006.

Swartz, E., Stockburger, L., and Vallero, D. A.: Polycyclic aromatic hydrocarbons and other semivolatile organic compounds collected in New York city in response to the events of 9/11, Environ. Sci. Technol., 37, 3537-3546, 2003.

Temime-Roussel, B., Monod, A., Massiani, C., and Wortham, H.: Evaluation of an annular denuder tubes for atmospheric $\mathrm{PAH}$ partitioning studies-1: evaluation of the trapping efficiency of gaseous PAHS, Atmos. Environ., 38, 1913-1924, 2004a.

Temime-Roussel, B., Monod, A., Massiani, C., and Wortham, H.: Evaluation of an annular denuder tubes for atmospheric PAH partitioning studies-2: evaluation of mass and number particle losses, Atmos. Environ., 38, 1925-1932, 2004b.

Turpin, B. J., Huntzicker, J. J., and Hering, S. V.: Investigation of organic aerosol sampling artifacts in the los angeles basin, Atmos. Environ., 28, 3061-3071, 1994.

Turpin, B. J., Saxena, P., and Andrews, E.: Measuring and simulating particulate organics in the atmosphere: problems and prospects, Atmos. Environ., 34, 2983-3013, 2000.

Turpin, B. J. and Lim, H. J.: Species contributions to PM2.5 mass concentrations: revisiting common assumptions for estimating organic mass, Aerosol Sci. Tech., 35, 602-610, 2001.

US EPA: Air Quality Criteria for Particulate Matter, Research Triangle Park, North Carolina, EPA/600/P-99/002aF, 2004.

Venkataraman, C. and Friedlander, S. K.: Size distributions of polycyclic aromatic hydrocarbons and elemental carbon. 2. ambient measurements and effects of atmospheric processes, Environ. Sci. Technol., 28, 563-572, 1994.

Viana, M., Chi, X., Maenhaut, W., Cafmeyer, J., Querol, X., Alastuey, A., Mikuška, P., and Večeřa, Z.: Influence of sampling artefacts on measured PM, OC, and EC levels in carbonaceous aerosols in an urban area, Aerosol Sci. Tech., 40, 107-117, 2006a.

Viana, M., Chi, X., Maenhaut, W., Querol, X., Alastuey, A., Mikuška, P., and Večeřa, Z.: Organic and elemental carbon concentrations in carbonaceous aerosols during summer and winter sampling campaigns in Barcelona, Spain, Atmos. Environ., 40, 2180-2193, 2006b.

Viana, M., Maenhaut, W., ten Brink, H. M., Chi, X., Weijers, E., Querol, X., Alastuey, A., Mikuška, P., and Večeřa, Z.: Comparative analysis of organic and elemental carbon concentrations in 
carbonaceous aerosols in three European cities, Atmos. Environ., 41, 5972-5983, 2007.

Wexler, A. S. and Johnston, M. V.: What have we learned from highly time-resolved measurements during EPA's Supersites program and related studies?, J. Air Waste Manage., 58, 303-319, 2008.

Wonaschütz, A., Hitzenberger, R., Bauer, H., Pouresmaei, P., Klatzer, B., Caseiro, A. and Puxbaum, H.: Application of the integrating sphere method to separate the contributions of brown and black carbon in atmospheric aerosols, Environ. Sci. Technol., 43, 1141-1146, 2009.
Yang, H. and Yu, J. Z.: Uncertainties in charring correction in the analysis of elemental and organic carbon in atmospheric particles by thermal/optical methods, Environ. Sci. Technol., 36, 51995204, 2002.

Yu, J. Z., Xu, J. H., and Yang, H.: Charring characteristics of atmospheric organic particulate matter in thermal analysis, Environ. Sci. Technol., 36, 754-761, 2002.

Zhang, Q., Streets, D. J., He, K. B., and Klimont, Z.: Major components of China's anthropogenic primary particulate emissions, Environ. Res. Lett., 2, 045027, doi:10.1088/17489326/2/4/045027, 2007. 